\title{
Unidade na bio-diversidade: diálogos com o bem-viver
}

\author{
Unity in bio-diversity: dialogues with the good-living
}

La unidad en la bio-diversidad: diálogos con el buen-vivir

\author{
Nathan Raphael Varotto ${ }^{1}$; Alice Maria Calado Melges ${ }^{2}$ LÚCio Castro Fábis $^{3}$ \\ UnIVERSIDAde Federal de São CaRlos, UFSCAR, SÃo CARLOS-SP, BRASIL
}

\begin{abstract}
RESUMO
Este ensaio se propõe a refletir sobre os princípios da filosofia do Bem-Viver, colocando-a em diálogo com ideias e proposições que visam a construção de alternativas para a superação da atual crise civilizatória, marcada pela degradação ambiental e social, naturalizadas, em que tudo se tolera em nome do tão sonhado e prometido desenvolvimento. O Bem-Viver se orienta a partir de valores que preconizam a cooperação, a solidariedade, a pluralidade e a democracia, e neste sentido se coloca como alternativa à crise ora mencionada. No intuito de avançar nesta reflexão, buscamos colocar o Bem-Viver em diálogo com ideias e conceitos que possam contribuir com o seu fortalecimento e construção práxica.
\end{abstract}

Palavras-chave: Bem-Viver. Motricidades. Ecologia de Saberes.

\begin{abstract}
This essay proposes to reflect on the principles of the philosophy of Good-Living, putting it in dialogue with ideas and propositions that aim at building alternatives to overcome the current civilizing crisis, marked by naturalized environmental and social devastation, where everything is tolerated in the name of the long-dreamed and promised development. Good-Living is based on values that advocate cooperation, solidarity, plurality and democracy, and in this sense it is placed as an alternative to the crisis just mentioned. In order to advance this reflection, we seek to place Good-Living in dialogue with ideas and concepts that can contribute to its strengthening and praxic construction.
\end{abstract}

Keywords: Good-Living. Motricities. Ecology of Knowledges.

\section{RESUMEN}

Este ensayo propone reflexionar sobre los principios de la filosofía del Buen-Vivir, poniéndolo en diálogo con ideas y propuestas que apuntan a construir alternativas para superar la actual crisis civilizadora, marcada por la devastación ambiental y social naturalizada, donde todo se tolera en nombre del desarrollo prometido y soñado durante mucho tiempo. El Buen-Vivir se guía por valores que abogan por la cooperación, la solidaridad, la pluralidad y la democracia, y en este sentido es una alternativa a la crisis que acabamos de mencionar. Para avanzar en esta reflexión, buscamos poner en diálogo el Buen-Vivir con ideas y conceptos que puedan contribuir a su fortalecimiento y construcción práxica.

Palabras clave: Buen-Vivir. Motricidades. Ecología de Saberes.

\footnotetext{
1 Doutorando em Educação pelo Programa de Pós-Graduação em Educação da UFSCar. E-mail: varotton@gmail.com. ORCID: http://orcid.org/0000-0002-6722-9083.

2 Mestranda em Educação pelo Programa de Pós-Graduação em Educação da UFSCar. E-mail: alice_mcm@hotmail.com. ORCID: http://orcid.org/0000-0003-4067-0554.

Doutorando em Educação pelo Programa de Pós-Graduação em Educação da UFSCar. E-mail: luciosfabis@gmail.com. ORCID: http://orcid.org/0000-0002-8789-5091.
} 


\section{ENSAIO}

O momento em que vivemos, marcado pela degradação ambiental, por uma extrema concentração de riqueza e enorme desigualdade social, intensificação das mudanças climáticas e crise sanitária proveniente da pandemia da COVID-19, evidenciam a existência de uma crise civilizatória e neste sentido faz um chamado, ou melhor, uma convocação, para que repensemos a nossa trajetória, modos de vida e valores que orientam o nosso ser-ao-mundo. Neste momento somos convidados a repensar nossa forma de viver e de nos relacionar a fim de evitar a queda do céu (KOPENAWA; ALBERT, 2015), que no pensamento indígena representaria o colapso da Vida.

Nosso modo de vida, resultante do sistema capitalista e de sua racionalidade, ao se orientar pelo antropocentrismo, acúmulo de capital e crença no progresso, nos levou a ver o ser humano como entidade atomizada e separada dos demais seres vivos, à valorização do ter sobre o ser e à negação da diversidade humana com suas formas de existência e produção de conhecimento. Essa lógica nos conduziu a um modo de vida nocivo às demais vidas do planeta, em que alguns seres humanos agem como se tudo existisse para lhes servir sem perceberem os prejuízos à sua própria vida, esvaziada de sentido e de historicidade, bem como à continuidade do mundo em sua bio-diversidade ${ }^{4}$.

Sabe-se que os colonizadores invadiram territórios e impuseram sua cultura, principalmente através do catolicismo; sabemos, também, que os padrões europeus vieram e foram impostos nesta Pindorama com a missão de catequizar e doutrinar os povos originários desta região, pela falácia da salvação divina. A partir deste momento histórico de apropriação e violência (SANTOS 2010), inicia-se mais um movimento de imposição cultural e de favorecimento do antropocentrismo.

Há um trecho da Bíblia, mais especificamente em Gênesis 1:26, que postula o seguinte: "Então disse Deus: 'Façamos o Homem à nossa imagem, conforme nossa semelhança. Domine ele sobre os peixes do mar, sobre as aves do céu, sobre os grandes animais de toda a terra e sobre todos os pequenos animais - que se movem rente ao chão" (BÍBLIA, 1990, p. 15). Consideramos um enorme equívoco tal passagem que serve como fundamentação para o antropocentrismo. Nesse ínterim entendemos que necessitamos estabelecer uma relação harmoniosa e horizontal com a Natureza, pois segundo Santos (2020) "[...] há muito mais vida no planeta do que a vida humana, já que esta representa apenas $0,01 \%$ da vida existente no planeta" (p. 31).

Nossa proposta neste ensaio é ressaltar a discussão de outra perspectiva de vida. Buscamos bases nos escritos de Alberto Acosta (2016) sobre o Bem-Viver, Ailton Krenak (2020) em "O amanhã não está à venda", Boaventura de Sousa Santos (2010) com as Epistemologias do Sul e Ecologia de Saberes e Manuel Sérgio (1999) com a Motricidade Humana em movimento intencional para transcendência por meio do Diálogo, do Esperançar e da Unidade na Diversidade de Paulo Freire (2011a). Portanto, no intuito de fortalecer e conectar essas narrativas e ideias é que caminhamos e escrevemos, a partir da colaboração, da reciprocidade e do respeito à diversidade e à Natureza.

O Bem-Viver aqui tratado tem como base os escritos e reflexões de Alberto Acosta, em seu livro: "O Bem Viver: uma oportunidade para imaginar outros mundos", publicado no Brasil, em 2016. O autor comenta que:

\footnotetext{
${ }^{4}$ Para nós, a bio-diversidade, ao destacar o termo bio, que significa vida, representa a diversidade em sua totalidade, abrangendo todas as formas de vida existentes na Terra.
} 
O Bem Viver - enquanto filosofia de vida - é um projeto libertador e tolerante, sem preconceitos nem dogmas. Um projeto que, ao haver somado inúmeras histórias de luta, resistência e propostas de mudança, e ao nutrir-se de experiências existentes em muitas partes do planeta, coloca-se como ponto de partida para construir democraticamente sociedades democráticas (ACOSTA, 2016, p. 29).

Trata-se de outra visão de mundo, de outra proposta de organização social, que tem nos saberes e vivências de povos indígenas sua inspiração, visto que desde o período colonial esses povos vêm resistindo e lutando para garantir a sobrevivência de sua cultura e sua gente.

Uma das principais propostas do Bem-Viver está no viver em comunidade e com a Natureza, tirando o foco do antropocentrismo e considerando que há mais vida além da humana; nesse ínterim, busca-se harmonia desde a bio-diversidade.

Partindo desta bio-diversidade é possível traçar relações entre o Bem-Viver e a Motricidade Humana, pois a partir de nossa ação motriz é que nos pomos a lutar por nossos interesses e manifestar nossas intenções. Ao incorporar esta outra perspectiva de mundo, retoma-se a conexão com a Natureza: abraçar a árvore, conversar com o rio, contemplar a montanha (KRENAK, 2020).

É comum a visão de que os povos indígenas dançam para elementos da MãeTerra, desde o sol, a chuva, a celebração da colheita, mesmo de algum fruto, mas também deve-se destacar sua atenção ao que lhe perpassa, sua percepção voltada ao mundo e ao que lhes/nos acontece/acomete. Pelo prazer de se movimentar em conexão com a Natureza, harmonicamente, sem qualquer tipo de desenvolvimento ou algo em troca, como envolvimento, como integralidade e coletividade vivente. Essa é uma possibilidade de aproximar o Bem-Viver e a Motricidade Humana; em acordo com a complexidade envolvida no Bem-Viver, talvez até deixe de ser Motricidade Humana e passe a ser, Motricidades, pois se estamos propondo deixar o antropocentrismo de lado, a Motricidade Humana, deixa de ter sentido diante da co-existência de outras vidas, que também se movem para a transcendência. O rio se movimenta, a árvore se movimenta, os animais se movimentam e a Terra, a partir desses movimentos que se retroalimentam, também se movimenta, garantindo a sobrevivência da bio-diversidade a partir das Motricidades.

Nesse sentido pode-se refletir sobre a intencionalidade com a qual os seres vivos se movimentam e (inter)agem. Freire (2019), ao teorizar sobre a historicidade da experiência humana no mundo, menciona haver uma diferença fundamental na forma como os animais e os seres humanos percebem e interagem com seu ambiente já que "[...] toda operação no mundo envolve uma certa compreensão dele" (p. 32).

Os animais, por estarem totalmente aderidos e imersos no ambiente em que vivem, não podem se separar dele para objetivarem a si próprios e às suas atividades; e sem esse nível de consciência, a vida dos animais passa a se dar sobre um suporte, de forma determinada e adaptativa (FREIRE, 2019). Com o ser humano, a situação é diferente: por ser capaz de emergir da realidade ele pode objetivar a si mesmo, as suas atividades e a sua relação com mundo - um mundo não determinado, em construção, que ao mesmo tempo em que constitui o ser humano é formado por ele (FREIRE, 2019).

Diante desta possibilidade de análise, cabe agora nos perguntarmos para qual direção esta Motricidade, em especial a Humana, está nos conduzindo em termos de mundo e humanidade, considerando a relação dialética existente na construção de ambos. 
A sociedade moderna ocidental negou e excluiu existências e saberes que diferiam do padrão hegemônico valorizado pelo sistema capitalista, colocando-os em situação periférica e marginal, processo que, segundo Santos (2010), estaria associado à formação do pensamento abissal que permeia a lógica da globalização neoliberal e invisibiliza outras lógicas e experiências do viver e conhecer.

Este pensamento, por meio da imposição de uma linha invisível, segrega e fragmenta a realidade social, mantendo de um lado da linha ${ }^{5}$ a classe dominante e do outro, todos os indivíduos e grupos que escapam ao padrão hegemônico, impondo a eles uma lógica social diferenciada daquela que é aplicada à classe dominante; uma lógica de negação de direitos, de existências e de produção de saberes, pautada na violência e na apropriação (SANTOS, 2010).

Krenak (2020), fazendo alusão a esta racionalidade sectária (embora não a denomine como pensamento abissal) nos faz refletir sobre o conceito de humanidade, apontando a contradição que existe entre a ideia de unidade e coesão que o conceito pressupõe e sua expressão na realidade social, marcada pela fragmentação, divisão e sectarismo. Seguindo em sua reflexão, o autor denuncia mais um aspecto deste conceito, que na cosmovisão indígena seria uma contradição: o pressuposto de segregação da espécie humana das demais, nos apartando daquilo que entendemos por Natureza, dentro de uma lógica radicalmente antropocêntrica que se opõe à ideia de biodiversidade anunciada pela filosofia do Bem-Viver.

Em meio a esta denúncia e refletindo sobre os motivos que nos conduziram, enquanto sociedade, à pandemia do novo coronavírus (Sars-CoV-2), Krenak (2020) nos aponta um caminho de transformação e saída da crise, que é sanitária, mas também humana: a reconexão entre os seres humanos e sua reintegração ao que denominamos por Natureza. Tomamos a cosmovisão indígena, legítima representante do Sul Global (SANTOS, 2010), como inspiração para a re-significação da nossa presença no mundo, a partir da construção de uma nova ética, para um novo sonho, um sonhar mais longe, como indicam Kopenawa e Albert (2015):

\begin{abstract}
Os brancos nos chamam de ignorantes apenas porque somos gente diferente deles. Na verdade, é o pensamento deles que se mostra curto e obscuro. Não consegue se expandir e se elevar, porque eles querem ignorar a morte. [...] Ficam sempre bebendo cachaça e cerveja, que lhes esquentam e esfumaçam o peito. É por isso que suas palavras ficam tão ruins e emaranhadas. Não queremos mais ouvi-las. Para nós, a política é outra coisa. São as palavras de Omama e dos xapiri que ele nos deixou. São as palavras que escutamos no tempo dos sonhos e que preferimos, pois são nossas mesmo. Os brancos não sonham tão longe quanto nós. Dormem muito, mas só sonham consigo mesmos (p. 390).
\end{abstract}

Estas reflexões indígenas expressam os princípios da filosofia do Bem-Viver, na medida em que esta pressupõe a superação do sistema capitalista por meio de uma racionalidade que se pauta em uma lógica ampla de cooperação, em que os seres humanos estão integrados entre si e com os demais seres vivos, para um novo mundo

\footnotetext{
5 Santos (2010) quando escreve o texto: "Para além do pensamento abissal: das linhas globais a uma ecologia de saberes" parte do Norte global e por isso, ao se referir à linha abissal, se posiciona "do lado de cá da linha", referindo-se ao Sul global ao tratar "do lado de lá da linha". Partimos do mesmo pressuposto e da mesma escala de análise, quando dizemos "do lado de cá da linha" nos referimos ao Sul global, onde estamos situados/as, e ao mencionarmos o "lado de lá da linha" fazemos menção ao Norte global.
} 
possível, em uma rede relacional que trabalha com a ideia de complementaridade e interculturalidade (ACOSTA, 2016).

$\mathrm{Na}$ lógica do Bem-Viver, o pensamento abissal se esvai, dando lugar ao que Santos (2010) denomina como Ecologia de Saberes. Nesta realidade social, os sujeitos e grupos que anteriormente eram tidos como marginais e periféricos e que por isso, eram excluídos e oprimidos pelo sistema capitalista, passam a coexistir com as classes dominantes, a partir da lógica da interculturalidade que se pauta na troca e intercâmbio de saberes, dentro de um contexto de reciprocidade e autonomia (SANTOS, 2010).

Este conceito faz referência ao estudo das relações que são estabelecidas pelos seres vivos, entre eles e destes com seu ambiente. Embora o texto tenha circunscrito este intercâmbio de saberes na espécie humana, dentro do que o autor chama de Ecologia de Saberes (SANTOS, 2010), o termo Ecologia nos convida para um olhar mais abrangente, considerando os demais seres vivos desta rede relacional de troca e também de interdependência, tendo como horizonte as ideias do Bem-Viver trazidas por Acosta (2016) e que permeiam as narrativas de Krenak (2020).

No que tange à Ecologia, e fazendo alusão às ideias de Capra (2006) sobre a “[...] teia da vida" (p. 231), pode-se dizer que a visão do eu como entidade separada e independente é uma ilusão que ignora as relações de conexão, cooperação e interdependência existentes entre os seres vivos e que ao fazer isso deixa de conceber a diversidade como elemento fundamental à manutenção dos ecossistemas, haja vista que a sua estrutura está fortemente associada à diversidade.

Quanto maior a diversidade de um ecossistema, maior a sua elasticidade e resiliência (capacidade de responder e resistir a distúrbios), pois neste caso há muitas espécies com funções ecológicas sobrepostas que poderiam, parcialmente, substituir umas às outras em caso de extinções locais (CAPRA, 2006). Diante dessa constatação, o autor extrapola esta reflexão, mostrando a importância da diversidade humana para a resiliência dos ecossistemas e do planeta, considerando o papel das relações humanas. Para ele, a diversidade é uma vantagem estratégica considerando os ecossistemas e as relações humanas que nela são estabelecidas.

A ruptura da racionalidade e do capitalismo almejada por Santos (2010), Acosta (2016) e Krenak (2020), se encontra na troca e conectividade de saberes em biodiversidade, na reciprocidade e cooperação. São pedras fundamentais para um caminho a ser trilhado; um caminho que não está pré-definido, mas que será construído ao caminhar, tendo como direção (ou como Sul) a utopia e o sonho de um mundo mais humano e solidário.

As Epistemologias do Sul propostas por Santos e Meneses (2010) - pois tanto na América Latina como em África, a partir do movimento de colonização introduziu-se apenas uma visão de mundo possível, a eurocêntrica - pretendem elucidar o Sul do mundo e mais, valorizar os conhecimentos aqui construídos. Nas palavras de Santos (1995): "[...] uma epistemologia do Sul assenta em três orientações: aprender que existe o Sul; aprender a ir para o Sul; aprender a partir do Sul e com o Sul” (p. 508).

Sendo assim, não nos era possível possuir conhecimento, apenas crenças, místicas, intuição e opinião infundadas a partir do que determinaram como verdadeiro e falso ou ciência e não-ciência; tudo isso para manterem a imagética de soberania, em detrimento da negação de outrem. Diante de muita luta deste lado da linha é que foi possível iniciar um movimento de mudança, pois pessoas lutaram para o reconhecimento e afirmação das Epistemologias do Sul. Para rompermos este abismo faz-se necessário continuarmos lutando para e por meio de Ecologia de Saberes (SANTOS, 2010), a qual não se trata apenas de mais um conceito e sim de um movimento político a fim de romper com a monocultura: 
[...] se baseia no reconhecimento da pluralidade de conhecimentos heterogéneos (sendo um deles a ciência moderna) e em interações sustentáveis e dinâmicas entre eles sem comprometer a sua autonomia. A ecologia de saberes baseia-se na ideia de que o conhecimento é interconhecimento (SANTOS, 2010, p. 53).

Quanto a essa Ecologia de Saberes, Krenak (2019) cobra a integração de "[...] nossas experiências cotidianas, escolhas sobre o lugar em que queremos viver, nossa experiência como comunidade" (p. 24), para que o consumo não tome o lugar daquilo que antes era cidadania. Kopenawa e Albert (2015), narrando um sonho de Davi Kopenawa, a partir de seu contato com a cidade dos "brancos" - Nova Iorque (EUA) chegam à conclusão:

\begin{abstract}
As pessoas vivem amontoadas umas em cima das outras e apertadas, excitadas como vespas no ninho. Tudo isso causa tontura e obscurece o pensamento. $\mathrm{O}$ barulho contínuo e a fumaça que cobre tudo impedem de pensar direito. Deve ser mesmo por isso que os brancos não conseguem nos ouvir! (p. 434).
\end{abstract}

Lembrando crítica realizada pelo ex-presidente uruguaio José Mujica quanto à cidadania, Krenak (2019) também questiona:

Então para que ser cidadão? Para que ter cidadania, alteridade, estar no mundo de maneira crítica e consciente, se você pode ser um consumidor? Essa ideia dispensa a experiência de viver numa terra cheia de sentido, numa plataforma para diferentes cosmovisões (p. 24-25).

Portanto, trata-se da identificação e revalorização dessa "[...] experiência de viver numa Terra cheia de sentido" (KRENAK, 2019, p. 25), em movimento (motricidade), de corpo-presente, em contraposição à sociologia das ausências (SANTOS, 2002).

\begin{abstract}
Nosso tempo é especialista em criar ausências: do sentido de viver em sociedade, do próprio sentido da experiência da vida. Isso gera uma intolerância muito grande com relação a quem ainda é capaz de experimentar o prazer de estar vivo, de dançar, de cantar. E está cheio de pequenas constelações de gente espalhada pelo mundo que dança, canta faz chover. $\mathrm{O}$ tipo de humanidade zumbi que estamos sendo convocados a integrar não tolera tanto prazer, tanta fruição de vida. Então pregam o fim do mundo como uma possibilidade de fazer a gente desistir dos nossos próprios sonhos. E a minha provocação sobre adiar o fim do mundo é exatamente sempre poder contar mais uma história. Se pudermos fazer isso, estaremos adiando o fim (KRENAK, 2019, p. 26-27).
\end{abstract}

Pensando nisso, como podemos "[...] experimentar o prazer de estarmos vivos, de dançar, de cantar" (KRENAK, 2019, p. 26) e ao mesmo tempo "[...] contar mais uma história” (KRENAK, 2019, p. 27)?

Esse "[...] sempre poder contar mais uma história" (KRENAK, 2019, p. 27) tem concretude enquanto história vivenciada e construída coletivamente, na passagem de potência a ato, movimento, em que tal motricidade (SÉRGIO, 1999), é a 
intencionalidade operante em nossas ações, nosso ser-ao-mundo, manifestada por nossa corporeidade em interação com-outrem-e-ao-mundo, "sociobiocêntrica" (ACOSTA, 2016), em resistência e transição; numa "unidade na diversidade" (FREIRE, 2011a), que abranja a bio-diversidade do mundo, para a qual nos movamos intencionalmente para tal transcendência.

É urgente "[...] viver a experiência da nossa própria circulação pelo mundo, não como uma metáfora, mas como fricção, poder contar uns com os outros" (KRENAK, 2019, p. 32), valorizar os saberes populares, a dialogicidade.

[...] o diálogo é uma exigência existencial. E, se ele é o encontro em que se solidarizam o refletir e o agir de seus sujeitos endereçados ao mundo a ser transformado e humanizado, não pode reduzir-se a um ato de depositar ideias de um sujeito no outro, nem tampouco tornar-se simples troca de ideias a serem consumidas pelos permutantes (FREIRE, 2011b, p. 109).

Vivamos o diálogo, como meio e fim, nesta unidade na bio-diversidade do BemViver (ACOSTA, 2016) entre os seres-ao-mundo, para que evitemos a queda do céu. Juntos e juntas podemos agir: "[...] para segurar a abóbada celeste [...] [e] impedir mais essa queda" (KOPENAWA; ALBERT, 2015, p. 194).

\section{REFERÊNCIAS}

ACOSTA, A. O bem viver: uma oportunidade para imaginar outros mundos. São Paulo: Autonomia Literária, 2016.

BÍBLIA. Gênesis. In: BÍBLIA. Sagrada bíblia católica: antigo e novo testamentos. São Paulo: Sociedade Bíblica Católica Internacional, 1990. p. 14-67.

CAPRA, F. A teia da vida: uma nova compreensão científica dos sistemas vivos. São Paulo: Cultrix, 2006.

FREIRE, P. À sombra desta mangueira. Paz e Terra: Rio de Janeiro, 2019.

FREIRE, P. Pedagogia da esperança: um retorno à pedagogia do oprimido. Paz e Terra: Rio de Janeiro, 2011a.

FREIRE, P. Pedagogia do oprimido. Paz e Terra: Rio de Janeiro, 2011 b.

KOPENAWA, D.; ALBERT, B. A queda do céu: palavras de um xamã yanomami. Trad. Beatriz Perrone-Moisés. São Paulo: Companhia das Letras, 2015.

KRENAK, A. O amanhã não está à venda. São Paulo: Companhia das Letras, 2020.

KRENAK, A. Ideias para adiar o fim do mundo. São Paulo: Companhia das Letras, 2019.

SANTOS, B. S. A cruel pedagogia do vírus. Coimbra: Almedina, 2020.

SANTOS, B. S. Para além do pensamento abissal: das linhas globais a uma ecologia de saberes. In: SANTOS, B. S.; MENESES, M. P. Epistemologias do sul. São Paulo: Cortez, 2010. p. 31-83.

SANTOS, B. S. Para uma sociologia das ausências e uma sociologia das emergências. Revista Crítica de Ciências Sociais, n. 63, p. 237-280, out. 2002.

SANTOS, B. S. Toward a new common sense: law, sciense and politics in the paradigmatic transition. Nova Iorque: Routledge, 1995. 
SANTOS, B. S.; MENESES, M. P. Introdução. In: SANTOS, B. S.; MENESES, M. P. Epistemologias do sul. São Paulo: Cortez, 2010. p. 15-27.

SÉRGIO, M. A racionalidade epistémica na educação física do século XX. In: SÉRGIO, M.; ROSÁRIO, T.; FEITOSA, A. M.; ALMADA, F.; VILELA, J.; TAVARES, V. O sentido e a acção. Lisboa: Instituto Piaget, 1999, p.11-30.

Recebido em: 30 nov. 2020.

Aprovado em: 19 abr. 2021. 